\title{
Effects of spatial scale and habitat on the diversity of diapausing wetland invertebrates
}

\author{
Raquel Fontoura Freiry ${ }^{1}$, Fernanda Mara Esquinatti ${ }^{1}$, Cristina Stenert $^{1}$, \\ Alexandre Arenzon ${ }^{2}$, Daryl L. Nielsen ${ }^{3}$, Leonardo Maltchik ${ }^{1, *}$ \\ ${ }^{1}$ Laboratory of Ecology and Conservation of Aquatic Ecosystems, University of Vale do Rio dos Sinos (UNISINOS), \\ 93022-000 São Leopoldo, RS, Brazil \\ ${ }^{2}$ Laboratory of Ecotoxicology, Ecology Center, Federal University of Rio Grande do Sul, 91501-970 Porto Alegre, RS, Brazil \\ ${ }^{3}$ The Murray-Darling Freshwater Research Centre, CSIRO Land and Water Flagship and La Trobe University, Wodonga, \\ University Drive, VIC 3690, Australia
}

\begin{abstract}
The community structure of aquatic invertebrates producing dormant propagules has been associated with both local and regional-scale factors in temporary wetlands. We explore how patterns in the diversity of drought-resistant aquatic invertebrates are related to different spatial scales in ponds with distinct plant structural complexities. We tested 3 hypotheses: (1) the finest spatial scale (fine-scale diversity) has the strongest contribution to diversity and composi-

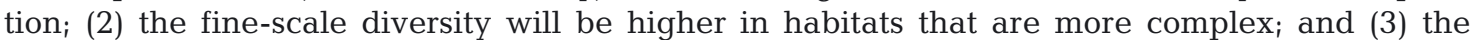
habitat-scale diversity has a higher contribution to regional diversity than broad- and fine-scale diversity. Dry sediment samples were collected from 3 ponds with 2 distinct plant habitats. The findings from individual partitions show that the importance of spatial scales was different between habitats. Fine-scale diversity represented a greater fraction of the total diversity for the habitat with the highest complexity, and broad-scale diversity showed a substantial contribution to total diversity in the habitat with the lowest complexity. Habitat-scale diversity contributed most to regional diversity, which underlines the importance of habitat type in the diversity of aquatic invertebrates that produce dormant propagules in temporary ponds.
\end{abstract}

KEY WORDS: Additive partitioning · Plant complexity · Dormancy · Egg bank · Temporary pond · Microcrustacean

\section{INTRODUCTION}

Wetlands are highly productive and support a rich biodiversity harboring many species with behavioral and physiological adaptations to endure hydrological fluctuations (Williams 2006). Dormancy during dry periods is a common solution to invertebrate survival and persistence in most temporary wetlands (Williams 1998), and dormant stages can remain viable in dry sediments for many years (De Stasio 1990). Invertebrate resting stages also provide a means of maintaining genetic, phenotypic, species and community diversity during unfavorable dry periods (Hairston 1996, Brendonck \& De Meester

\footnotetext{
*Corresponding author: maltchik@unisinos.br
}

2003, Santangelo 2009), and as a consequence of their longevity, they integrate spatial and temporal variations in community composition, which confers a measure of community resilience to adverse conditions (Brock et al. 2003).

Wetland ecosystems typically have high macrophyte diversity (Cronk \& Fennessy 2001) resulting in highly heterogeneous and structurally complex habitats (Mormul et al. 2011). Habitat complexity of wetlands results from distinct habitats of dominant vegetation types (e.g. submerged, emergent, floating) that directly affect the occurrence and distribution of aquatic invertebrates (Cheruvelil et al. 2000, 2002, Thomaz et al. 2008, Dibble \& Thomaz 2009). The

(C) The authors 2016. Open Access under Creative Commons by Attribution Licence. Use, distribution and reproduction are unrestricted. Authors and original publication must be credited. 
structural complexity generated by aquatic plants provides refuge for invertebrates, making them less vulnerable to predation, and also suitable breeding and foraging substrates (Gilinsky 1984). Therefore, invertebrate diversity and abundance are often positively correlated with the structural complexity provided by different wetland macrophyte species (Stenert et al. 2008, Thomaz \& Cunha 2010, LucenaMoya \& Duggan 2011, Mormul et al. 2011).

Aquatic invertebrate communities are structured by processes prevailing at multiple spatial scales (Minshall 1988, Poff 1997, Heino et al. 2003, Ligeiro et al. 2010). The relationship between invertebrate diversity and macrophyte complexity can change among different spatial scales (Thomaz \& Cunha 2010). For example, at finer spatial scales (e.g. among macrophyte beds of a small lake or even plants located close to each other), the invertebrate density and diversity varies depending on plant structural complexity (McAbendroth et al. 2005, Thomaz et al. 2008). At a fine scale, the distribution patterns of invertebrates in wetlands has been linked to biotic interactions, habitat heterogeneity and complexity, surface area, hydroperiod, and nutrient concentration (Heino 2000, Tarr et al. 2005, Mormul et al. 2011). Although aquatic ecosystems with different levels of complexity can present distinct patterns of species spatial distribution (Taniguchi \& Tokeshi 2004), most studies that have addressed the importance of habitat complexity in diversity were developed on a single spatial scale related to local variables.

The additive partitioning of species diversity is a promising approach to identify the most important sources of biologic diversity in a sampling design of nested spatial scales (Godfray \& Lawton 2001). Whittaker $(1960,1972)$ suggested that biological diversity can be divided into 3 components: alpha (local diversity), beta (variation among sites) and gamma (regional diversity). Lande (1996) and Crist et al. (2003) applied the diversity terms of Whittaker to the additive partition approach, where gamma diversity is obtained by summing the alpha and beta diversities. Since the ecological patterns of a community in a small spatial scale (local) might be different from those observed over broader spatial scales (landscapes or regions) (Crist et al. 2003, Heino et al. 2003), partitioning diversity allows the identification of spatial scales associated with the highest variation in species composition. Recently, the additive partitioning of diversity was used to test scale-dependent patterns of macroinvertebrate diversity in streams (Ligeiro et al. 2010) and coastal wetlands (Ávila et al. 2011) and demonstrated strong evidence of scale dependence on diversity partitioning of macroinvertebrate communities, with beta diversity at the broad spatial scale making a large contribution to total diversity.

In temporary wetlands, the relationship between invertebrate propagule banks and macrophyte complexity over different spatial scales has not been investigated, although it has been demonstrated that differences in the community structure of dormant propagules is associated with both local and regionalscale factors (Angeler et al. 2008, Fernández et al. 2009). In this study, we explore how patterns in the diversity and composition of drought-resistant aquatic invertebrates are related to different spatial scales (sediment cores, plant habitats and ponds) in ponds with distinct plant structural complexities. We used the additive partitioning approach to test 3 hypotheses: (1) the finest spatial scale (fine-scale diversity) has the strongest contribution to diversity and composition of drought-resistant aquatic invertebrates due to their poor active dispersal capacity (Fernández et al. 2009); (2) the fine-scale diversity will be higher in habitats that are more complex, where higher plant structural complexity increases the invertebrate diversity (Thomaz et al. 2008, Dibble \& Thomaz 2009); and (3) the habitat-scale diversity has a higher contribution to regional invertebrate diversity than the broad and fine scales, since the invertebrate diversity and composition changes among macrophyte beds of a same small pond, depending on plant structural complexity (McAbendroth et al. 2005, Thomaz et al. 2008).

\section{MATERIALS AND METHODS}

\section{Study area}

The study was conducted in Bom Jesus county $\left(28^{\circ} 40^{\prime} 04^{\prime \prime} \mathrm{S}, 50^{\circ} 25^{\prime} 00^{\prime \prime} \mathrm{W}\right)$, located in the Planalto Superior of Rio Grande do Sul, southern Brazil, an area known as altitude fields ('Campos de Cima da Serra') (altitude $\sim 1200 \mathrm{~m}$ ). The study area vegetation comprises natural pastures with dominance of natural grasslands and patches of mixed ombrophyllous forest (Araucaria forest). The altitude fields are located in the southern portion of the Mata Atlântica Biome. The wetlands of altitude fields are typically small (1-3 ha) and strongly affected by precipitation and evaporation. The climate is classified as super humid temperate. The mean annual temperature is $14.5^{\circ} \mathrm{C}$, but sub-freezing temperatures may occur from April to November (Backes 1999). The mean annual 
rainfall varies from 1500 to $1700 \mathrm{~mm}$, without a marked dry season (Bond-Buckup et al. 2010).

\section{Experimental design}

In the austral summer of 2014, 3 natural temporary ponds were selected, in each of which 2 distinct dominant plant habitats with differing structural complexity occurred: stands of Peruvian watergrass Luziola peruviana, characterized as the 'habitat with the lowest complexity', and Sphagnum bog, characterized as the 'habitat with the highest complexity'. Sphagnum bog is dominated by a dense growth of Sphagnum sp. moss, which forms a heterogenic and architecturally denser and more complex habitat compared with Peruvian watergrass habitat (Kuczyńska-Kippen 2008). The minimum area occupied by each distinct plant habitat was approximately $30 \%$ of the total area of each pond. All ponds had similar areas $(\sim 1 \mathrm{ha})$, water depth $(\sim 0.4 \mathrm{~m})$ and hydroperiods ( $\sim 6$ mo with surface water in a year). Ponds were located from 3 to $10 \mathrm{~km}$ from each other.

Sampling was hierarchical and included sediment cores, habitats and ponds (Fig. 1). Within each pond, 3 random cores were taken from each of the 2 habitats (6 samples per pond) (Fig. 1). We used modified methods by Ávila et al. (2015) and Stenert et al.

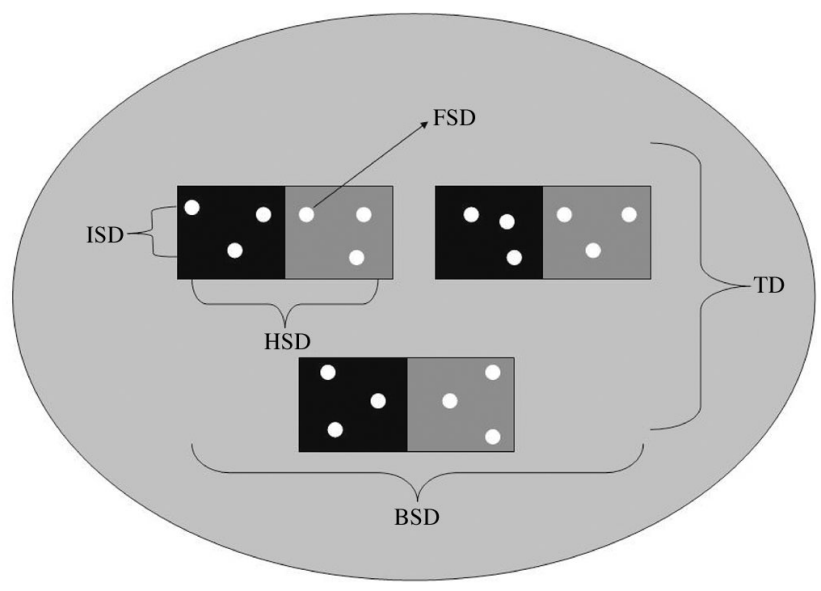

Fig. 1. Schematic representation of sampling design and diversity partition among and within the 3 ponds. Fine-scale diversity $(\mathrm{FSD})=$ mean invertebrate richness per individual core; intermediate-scale diversity (ISD) = differences of invertebrate taxa between cores; habitat-scale diversity (HSD) = differences of invertebrate taxa between habitats; broadscale diversity $(\mathrm{BSD})=$ differences of invertebrate taxa between ponds; TD = total diversity. Black squares represent the habitat with the highest plant complexity and grey squares represent the habitat with the lowest plant complexity
(2016). In brief, dry sediment sampled per habitat in each pond was homogenized and distributed into plastic trays, totaling 18 trays ( 3 samples $\times 2$ habitats $\times 3$ ponds). In an experimental room, the trays were flooded with distilled water and stored at constant temperature and photoperiod over $21 \mathrm{~d}$. Aquatic invertebrates were sampled on Days 2, 7, 14 and 21. Three sweeps were performed in each tray and the sampled invertebrates were preserved with $80 \%$ ethanol (Ávila et al. 2015, Stenert et al. 2016) and identified to species level (cladocerans) and lower taxonomic resolutions (ostracods and copepods) according to Elmoor-Loureiro (1997). The invertebrates were deposited in the Laboratory of Ecology and Conservation of Aquatic Ecosystems of University of Vale do Rio dos Sinos (UNISINOS).

\section{Data analysis}

Invertebrate richness was compared between the 2 habitats over time (using ponds as replicates) using repeated-measures ANOVA. Where significant differences between habitats were indicated, Tukey tests were applied a posteriori for multiple comparisons among the different days after initial sediment rehydration. Richness data were transformed to square root prior to statistical analyses to ensure normality of the data set and equality of variances. The Levene's test verified the homogeneity of variance assumption, and the Mauchy's test of sphericity verified the sphericity assumption. Assuming compound symmetry (homogeneity of the variance-covariance matrix), no adjustment was made for the F-test. Analyses were performed using SPSS software, version 18.0 (SPSS 2009).

Non-metric multidimensional scaling analysis (NMDS) was used to assess the variation in invertebrate community composition between the 2 habitats throughout the experiment (Clarke \& Warwick 1994). This analysis was performed with the Sorensen distance matrix (presence and absence data) using 2 axes in the $\mathrm{R}$ statistical program ( $\mathrm{R}$ Development Core Team 2009). A 2-way permutational multivariate analysis of variance (PERMANOVA) (Anderson 2001) was used to compare differences in the community composition between the 2 habitats over time (habitat effect + time effect + habitat $\times$ time interaction effect). We used the Sorensen distance matrix and 9999 permutations to validate the model significance. The analyses were carried out using the vegan package (Oksanen et al. 2009) in the statistical software R version 2.9.0 (R Development Core Team 2009). 
Additive partitioning of diversity was used to decompose the total variation in community composition (regional diversity) into different spatial scales of diversity. In our study, individual rehydrated cores represent our basic units. The invertebrate diversity was analyzed at 3 different spatial scales: (1) the finest spatial scale was the location-induced diversity and corresponded to the individual cores in each habitat $(\mathrm{n}=18)$; (2) the intermediate spatial scale was the plant-community-induced diversity and corresponded to the 3 cores collected in each habitat ( $\mathrm{n}=$ 9); and (3) the broader spatial scale was the pondinduced diversity and corresponded to the individual ponds $(\mathrm{n}=3$ ) (Fig. 1). Therefore, the total diversity was partitioned into the average diversity (expressed as a percentage) within individual rehydrated cores, defined as the average richness per basic unit (finescale diversity), between rehydrated cores (represented by the differences of invertebrate taxa collected in the basic units (intermediate-scale diversity) and between ponds (broad-scale diversity).

Partition analyses were performed to compare the relative contribution of each spatial scale between the habitats with the lowest and highest plant complexities. For this, the data were analyzed separately for each plant habitat. A partition analysis was also performed to verify the habitat-scale diversity contri- bution compared with the other spatial scales (Fig. 1). The additive partition analyses were performed using PARTITION version 3.0 (Veech \& Crist 2007), and the statistical procedures are detailed by Ávila et al. (2015). Since the samples at the highest spatial scale (ponds) contain the same number of samples at the habitat spatial scale, the sampling design was balanced in the analyses.

\section{RESULTS}

A total of 3312 individuals from 14 taxa were collected over the experiment. All invertebrates that emerged from dormant propagules were microcrustaceans. Dominant microcrustaceans were cladoceran species, which were represented by 3043 individuals and 12 species. The most abundant cladoceran species were Macrothrix elegans and Ilyocryptus spinifer, representing 46 and $26 \%$ of the individuals sampled, respectively. Kurzia polyspina and Chydorus eurynotus were the most abundant species of chydorids. Calanoid copepods and ostracods were also found over the experiment (Table 1).

The timing of emergence of the invertebrate species varied between the habitats with the lowest and highest complexity over the experiment. The first

Table 1. Total numbers of drought-resistant aquatic invertebrates that emerged from habitats with the lowest and highest plant complexity in pond sediments of southern Brazil following rehydration (Days 2, 7, 14 and 21)

\begin{tabular}{|c|c|c|c|c|c|c|c|c|c|}
\hline \multirow[t]{2}{*}{ Taxa } & \multicolumn{4}{|c|}{ Highest plant complexity } & \multicolumn{4}{|c|}{ Lowest plant complexity } & \multirow[t]{2}{*}{ Total abundance } \\
\hline & 2 & 7 & 14 & 21 & 2 & 7 & 14 & 21 & \\
\hline \multicolumn{10}{|l|}{ Cladocera } \\
\hline Alona ossiani & 0 & 0 & 4 & 6 & 0 & 0 & 0 & 1 & 11 \\
\hline Camptocercus similis & 0 & 1 & 3 & 15 & 0 & 0 & 2 & 16 & 37 \\
\hline Ceriodaphnia silvestrii & 0 & 3 & 0 & 10 & 0 & 0 & 0 & 1 & 14 \\
\hline Chydorus eurynotus & 0 & 1 & 5 & 143 & 0 & 0 & 1 & 3 & 153 \\
\hline Ephemeroporus tridentatus & 0 & 0 & 6 & 10 & 0 & 1 & 2 & 9 & 28 \\
\hline Ilyocryptus spinifer & 10 & 43 & 69 & 304 & 0 & 10 & 53 & 289 & 778 \\
\hline Karualona muelleri & 0 & 0 & 4 & 24 & 0 & 0 & 1 & 1 & 30 \\
\hline Kurzia polyspina & 0 & 1 & 30 & 134 & 0 & 0 & 0 & 2 & 167 \\
\hline Leberis davidi & 0 & 12 & 2 & 3 & 1 & 0 & 2 & 3 & 23 \\
\hline Macrothrix elegans & 4 & 80 & 137 & 869 & 0 & 5 & 34 & 179 & 1308 \\
\hline Pseudosida bidentata & 9 & 17 & 40 & 138 & 0 & 0 & 0 & 0 & 204 \\
\hline Simocephalus serrulatus & 1 & 8 & 15 & 245 & 0 & 1 & 0 & 20 & 290 \\
\hline Calanoids & 0 & 111 & 95 & 60 & 0 & 0 & 0 & 0 & 266 \\
\hline Ostracods & 0 & 0 & 0 & 0 & 2 & 0 & 0 & 1 & 3 \\
\hline Total richness & 4 & 10 & 12 & 13 & 2 & 4 & 7 & 12 & 14 \\
\hline Total abundance & 24 & 277 & 410 & 1961 & 3 & 17 & 95 & 525 & 3312 \\
\hline
\end{tabular}


Table 2. Results of ANOVA and PERMANOVA tests for the effects of habitat, time and the interaction between habitat and time on the invertebrate richness and composition in altitude ponds in southern Brazil

\begin{tabular}{|llccccc|}
\hline Dependent & Independent & df & SS & MS & $F$ & p \\
\hline Richness & Habitat & 1 & 11.221 & 11.221 & 9.238 & 0.038 \\
& Residual & 4 & 4.859 & 1.215 & & \\
& Time & 3 & 8.456 & 2.819 & 6.391 & 0.008 \\
& Habitat $\times$ Time & 3 & 0.661 & 0.220 & 0.499 & 0.690 \\
& Residual & 12 & 5.293 & 0.441 & & \\
Composition & Habitat & 1 & 0.698 & 0.698 & 5.328 & 0.001 \\
& Time & 3 & 0.640 & 0.213 & 1.628 & 0.129 \\
& Habitat $\times$ Time & 3 & 0.691 & 0.230 & 1.758 & 0.122 \\
& Residual & 11 & 1.441 & 0.131 & & \\
\hline
\end{tabular}

taxa that emerged from sediments of the habitat with the lowest plant complexity were Leberis davidi and the ostracods ( $48 \mathrm{~h}$ of sediment re-wetting), and the species that emerged late were Ceriodaphnia silvestris, K. polyspina and Alona ossiani ( $21 \mathrm{~d}$ of sediment re-wetting). In the habitat with the highest plant complexity, 4 species emerged after the first 48 h (I. spinifer, Simocephalus serrulatus, M. elegans, and Pseudosida bidentata). All taxa found in the habitat with the highest complexity emerged within the first $14 \mathrm{~d}$ of sediment re-wetting. P. bidentata and calanoids emerged only in the habitat with the highest plant complexity. The most abundant species were I. spinifer and M. elegans for both pond habitats.

The invertebrate richness was higher in the habitat with the highest plant complexity over the experiment $\left(F_{1,4}=9.238 ; \mathrm{p}=0.038\right)$ (Table 2, Fig. 2). The richness also changed over the duration of the experiment $\left(F_{3,12}=6.391, \mathrm{p}=0.008\right)$, and it was higher after $21 \mathrm{~d}$ of sediment re-wetting than in the first week $(2$ and $7 \mathrm{~d}$

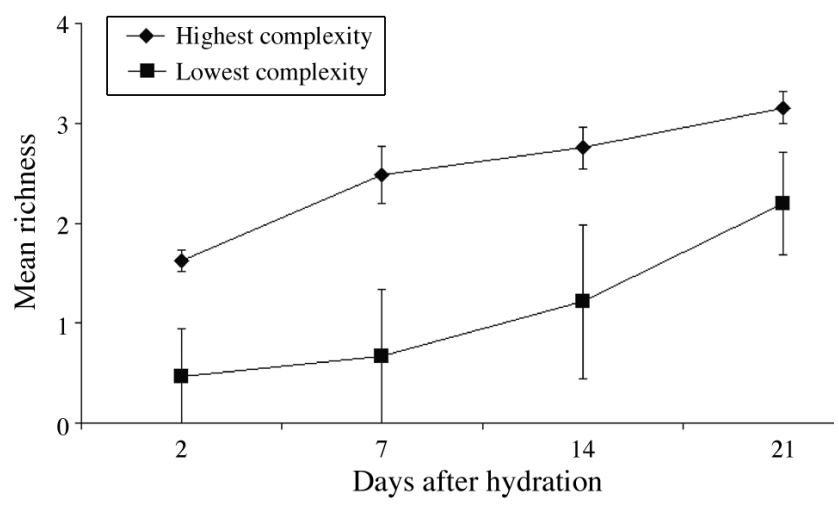

Fig. 2. Invertebrate richness (mean $\pm \mathrm{SE}$ ) of dormant propagules of aquatic invertebrates in altitude ponds in southern Brazil over the experiment in habitats with the lowest and highest plant complexity following the dry sediment hydration after re-wetting) $(\mathrm{p}<0.05)$. No interaction between habitat and time was observed in invertebrate richness $\left(F_{3,12}=0.499, \mathrm{p}=\right.$ 0.690) (Table 2, Fig. 2).

The dissimilarity of invertebrate composition between the habitats with the lowest and highest plant complexity over the experiment was represented by 2 axes of the NMDS ordination (stress = 0.09) (Fig. 3). The composition of the communities that emerged from propagule banks differed between the habitats with the lowest and highest plant complexity $\left(F_{1,11}=5.328 ; \mathrm{p}=0.001\right)$. However, the composition did not change over the experiment $\left(F_{3,11}=1.628 ; \mathrm{p}=0.129\right)$. No interaction between habitat and time was observed in invertebrate composition $\left(F_{3,11}=1.758 ; \mathrm{p}=0.122\right)$, showing that the composition variation between habitats was independent of time (Table 2).

Partitioning of invertebrate diversity showed similar patterns for both pond habitats. The fine-scale diversity was lower than expected from the null

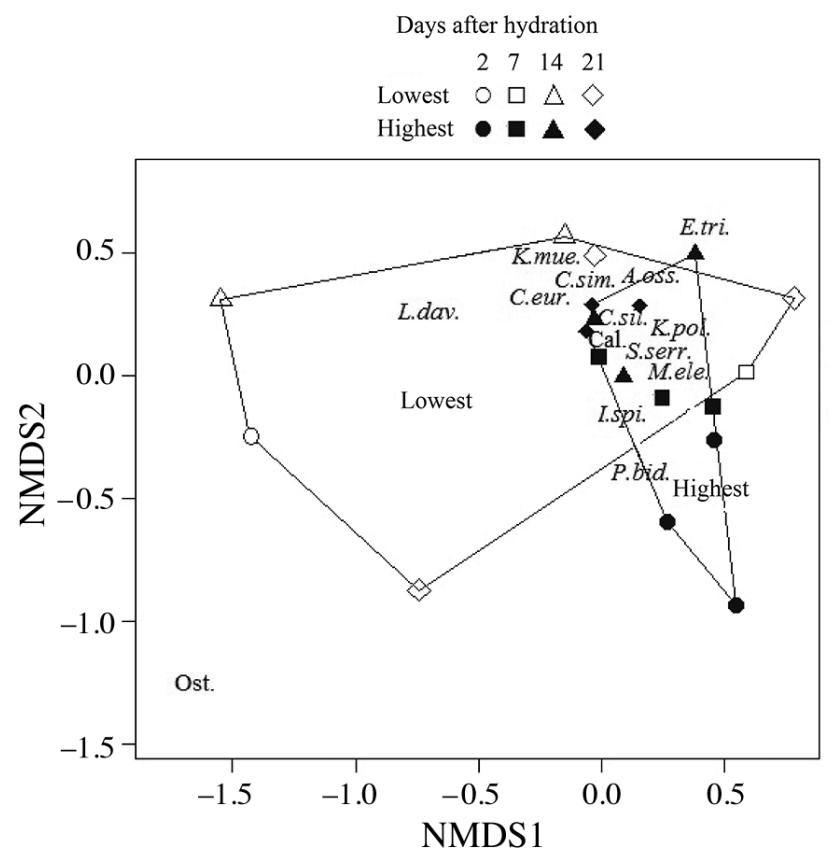

Fig. 3. NMDS ordination diagram of aquatic invertebrate taxa found in habitats with the lowest and highest plant complexity (stress: 0.09). A.oss.: Alona ossiani; C.eur.: Chydorus eurynotus; C.sil.: Ceriodaphnia silvestris; C.sim.: Camptocercus similis; E.tri.: Ephemeroporus tridentatus; K.mue.: Karualona muelleri; K.pol.: Kurzia polyspina; I.spi.: Ilyocriptus spinifer; L.dav.: Leberis davidi; M.ele.: Macrothrix elegans; P.bid.: Pseudosida bidentate; S.ser.: Simocephalus serrulatus, Cal.: Calanoid, Ost.: Ostracoda 

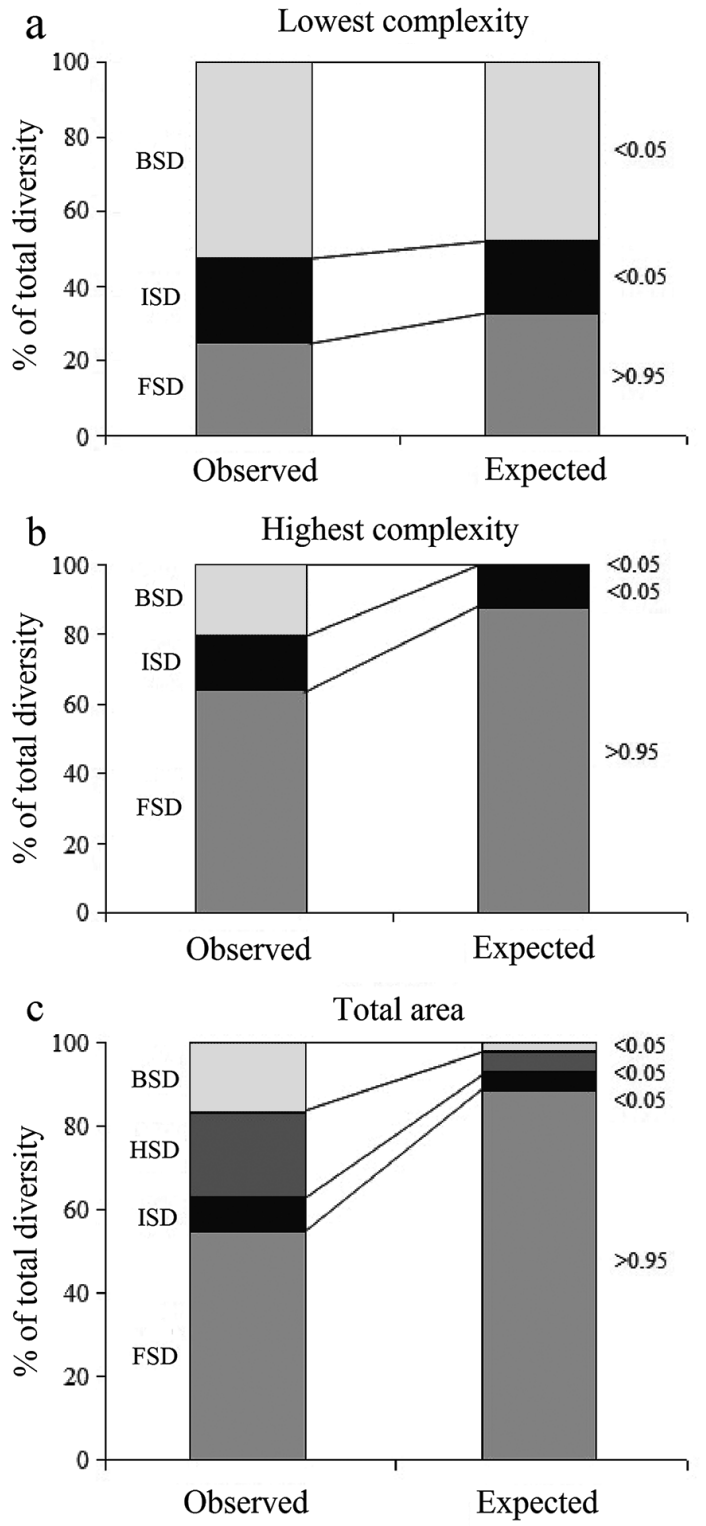

Fig. 4. Observed and expected diversity, partitioned into different spatial scales of diversity, expressed as percentage of total richness in (a) habitat with the lowest complexity, (b) habitat with the highest complexity and (c) total area. For individual partitions per habitat (a and b). See Fig. 1 for abbreviations and description of diversity scales. The numbers indicate the proportion of expected samples containing more species than the observed sample for each partition

model ( $p>0.95)$, but the intermediate and broad scales of diversity were higher than expected from the null model ( $\mathrm{p}<0.05$ ) (Fig. 4a,b). The fine-scale diversity represented a greater fraction of the total diversity for the habitat with the highest complexity $(64.08 \%)$. However, in the habitat with the lowest complexity, this spatial scale represented a smaller fraction of the total diversity $(25 \%)$. The intermediate and broad scales of diversity had different contribu- tions between pond habitats (habitat with the highest complexity: intermediate-scale diversity $=15.38 \%$, broad-scale diversity $=20.54 \%$; habitat with the lowest complexity: intermediate-scale diversity $=22.25 \%$, broad-scale diversity $=52.75 \%$ ). The invertebrate diversity and composition variations between ponds (broad-scale diversity) were higher in the habitat with the lowest complexity than in the habitat with the highest complexity (Figs. $3 \& 4 a, b)$. These results showed that the differences of invertebrate taxa might change depending on the scale of study in different habitat types.

The results of the second partition analysisincluding the habitat type as an additional level in the hierarchical design - showed that while the finescale diversity was lower than expected under the null model ( $p$ > 0.95), the other scales of invertebrate diversity (intermediate, habitat and pond scales) were significantly higher than expected from the null model ( $\mathrm{p}<0.05$ ) (Fig. 4c). In relation to the contribution from each spatial scale for total diversity, the fine-scale diversity was higher than the other diversity scales, representing the greatest fraction of the total invertebrate diversity $(54.79 \%)$, followed by the habitat scale $(20.07 \%)$ and the pond scale $(17.07 \%)$. The intermediate-scale diversity represented the lowest contribution to total diversity (8.07\%) (Fig. 4c).

\section{DISCUSSION}

Our results showed that the fine-scale diversity was lower than expected from the null model for both habitats, thus indicating high aggregation among invertebrates at fine spatial scales. This pattern may be related to the poor active dispersal capacity of drought-resistant aquatic invertebrates (Hairston 1996, Fernández et al. 2009), and also to the concentrated deposition of eggs in the sediment, reaching thousands of eggs per $\mathrm{m}^{2}$ (Santangelo 2009). A similar result has been demonstrated for zooplankton communities of tropical rivers during drought and flooding periods (Melo \& Medeiros 2013).

Our first hypothesis - the finest spatial scale contributed most to the diversity and composition of drought-resistant aquatic invertebrates - was partially accepted because the importance of this particular spatial scale varied between habitats. The finescale diversity was higher in the habitat with the highest complexity, where higher plant structural complexity provides a variety of microhabitats, thus creating more available ecological niches for associated animals (Warfe \& Barmuta 2004, Hansen et al. 
2011). On a fine spatial scale, a high plant complexity can increase the aquatic invertebrate diversity (Thomaz \& Cunha 2010). In the habitat with the lowest complexity, the fine-scale diversity represented a smaller fraction of the total diversity compared with the broad-scale diversity. These results supported our second hypothesis i.e. that the fine-scale diversity contributed more to the total invertebrate diversity in the habitat with the highest plant complexity.

Our third hypothesis was refuted since the habitatscale diversity had a similar contribution to regional invertebrate diversity compared with the broad spatial scale, and a lower contribution than the fine scale. However, this study clearly indicates that more complex habitats do not only harbor a higher diversity of invertebrates, but also contribute to the recovery of communities from dormant propagules more efficiently than less complex habitats. Other studies also observed a positive relationship between habitat complexity and species diversity (Thomaz et al. 2008, Hansen et al. 2011, Mormul et al. 2011, Choi et al. 2015). Kuczyńska-Kippen (2008) found that more diverse and abundant zooplankton communities occurred in the Sphagnum mat in relation to the openwater zone in a lake of northern Poland. Henrikson (1993) demonstrated that Sphagnum bogs supported a 10-fold increase in Cladocera abundance compared with less complex habitats. Not only are Sphagnum bogs more structurally complex, they are habitats subject to prolonged water saturation (Silva 2002) and allow for longer flooded periods and refuge creation for aquatic invertebrates.

The ability of the dormant propagules to rapidly respond to rehydration was observed in this study. A fast emergence response of dormant propagules is an important characteristic of aquatic invertebrates in intermittent wetlands (Golladay et al. 1997), and a response of invertebrates within $48 \mathrm{~h}$ of re-wetting has been previously reported (Boulton \& Lloyd 1992, Nielsen et al. 2000, Brock et al. 2003, Williams 2006, Ávila et al. 2015). However, the timing of invertebrate emergence varied between the species of the habitats with the lowest and highest complexity. In the habitat with the highest complexity, Ilyocryptus spinifer, Macrothrix elegans, Simocephalus serrulatus and Pseudosida bidentata emerged in the initial $48 \mathrm{~h}$ after the sediment rehydration; in the habitat with the lowest complexity, only Leberis davidi and ostracods emerged in the same period. The hatching dynamics of dormant propagules in the sediment can be influenced by the life history of the species, hatching phenology, and habitat and microhabitat characteristics (Brendonck \& De Meester 2003).
Studies using dormant stages are useful for the analysis of wetland diversity since they enable the sampling of a larger number of species than active forms (Mergeay et al. 2006) and also integrate much of the spatial and seasonal variation in the richness, abundance and composition of aquatic invertebrate species (Brendonck \& De Meester 2003). Our findings clearly indicated that there was a strong evidence of scaling dependence on diversity partition of aquatic invertebrates that produce dormant propagules. Our study has enabled the identification of the spatial scales that contribute most to the aquatic invertebrate community diversity as well as the influence of habitat structural complexity on community structuring. We believe that future studies in a more extensive area with a large number of ponds are important to further confirm our results.

Acknowledgements. We thank Francisco Diogo Rocha Sousa for collaboration in the identification of the microcrustaceans. L.M. and C.S. hold a Brazilian Research Council CNPq Research Productivity grant. We declare that the data collection complied with the Brazilian current laws. This work was supported by funds from Universidade do Vale do Rio dos Sinos - UNISINOS (grant number 02.00.023/00-0) and Conselho Nacional de Desenvolvimento Científico e Tecnológico - CNPq (grant number 52370695.2).

\section{LITERATURE CITED}

Anderson MJ (2001) A new method for non-parametric multivariate analysis of variance. Austral Ecol 26:32-46

Angeler DG, Viedma O, Sánchez-Carrillo S, AlvarezCobelas M (2008) Conservation issues of temporary wetland Branchiopoda (Anostraca, Notostraca: Crustacea) in a semiarid agricultural landscape: What spatial scales are relevant? Biol Conserv 141:1224-1234

Ávila AC, Stenert C, Maltchik L (2011) Partitioning macroinvertebrate diversity across different spatial scales in southern Brazil coastal wetlands. Wetlands 31:459-469

Ávila AC, Boelter T, Santos RM, Stenert C, Würdig NL, Rocha O, Maltchik L (2015) The effects of different rice cultivation systems and ages on resting stages of wetland invertebrates in southern Brazil. Mar Freshw Res 66: 276-285

Backes A (1999) Condicionamento climático e distribuição geográfica de Araucaria angustifolia (Bertol.) Kuntze no Brasil - II. Pesquisas. Botânica 49:31-52

Bond-Buckup G, Buckup L, Dreier C (2010) Biodiversidade dos Campos de Cima da Serra. Libretos, Porto Alegre

Boulton AJ, Lloyd LN (1992) Flooding frequency and invertebrate emergence from dry floodplain sediments of the River Murray, Australia. Regul Rivers Res Manage 7: 137-151

*Bendonck L, De Meester L (2003) Egg banks in freshwater zooplankton: evolutionary and ecological archives in the sediment. Hydrobiologia 491:65-84

* Brock MA, Nielsen DL, Shiel RJ, Green JD, Langley JD (2003) Drought and aquatic community resilience: the role of eggs and seeds in sediments of temporary wet- 
lands. Freshw Biol 48:1207-1218

Cheruvelil KS, Soranno PA, Serbin RD (2000) Macroinvertebrates associated with submerged macrophytes: sample size and power to detect effects. Hydrobiologia 441: 133-139

Cheruvelil KS, Soranno PA, Madsen JD, Roberson MJ (2002) Plant architecture and epiphytic macroinvertebrate communities: the role of an exotic dissected macrophyte. J N Am Benthol Soc 21:261-277

Choi JY, Kim SK, Jeng KS, Joo GJ (2015) Detecting response patterns of zooplankton to environmental parameters in shallow freshwater wetlands: discovery of the role of macrophytes as microhabitat for epiphytic zooplankton. J Ecol Environ 38:133-143

* Clarke KR, Warwick RM (1994) Similarity-based testing for community pattern: the two-way layout with no replication. Mar Biol 118:167-176

Crist TO, Veech JA, Gering JC, Summerville KS (2003) Partitioning species diversity across landscapes and regions: a hierarchical analysis of $\alpha, \beta$, and $\gamma$ diversity. Am Nat 162:734-743

Cronk JK, Fennessy MS (2001) Wetland plants: biology and ecology. CRC Press, Boca Ratón, FL

* De Stasio BT Jr (1990) The role of dormancy and emergence patterns in the dynamics of a freshwater zooplankton community. Limnol Oceanogr 35:1079-1090

* Dibble ED, Thomaz SM (2009) Use of fractal dimension to assess habitat complexity and its influence on dominant invertebrates inhabiting tropical and temperate macrophytes. J Freshw Ecol 24:93-102

Elmoor-Loureiro LMA (1997) Manual de identificação de cladóceros límnicos do Brasil. Universa, Brasília

*Fernández AI, Viedma O, Sánchez-Carrillo S, AlvarezCobelas M, Angeler DG (2009) Local and landscape effects on temporary pond zooplankton egg banks: conservation implications. Biodivers Conserv 18:2373-2386

Gilinsky E (1984) The role of fish predation and spatial heterogeneity in determining benthic community structure. Ecology 65:455-468

Godfray HCJ, Lawton JH (2001) Scale and species numbers. Trends Ecol Evol 16:400-404

* Golladay SW, Taylor BW, Palik BJ (1997) Invertebrate communities of forested limesink wetlands in southwest Georgia, USA: habitat use and influence of extended inundation. Wetlands 17:383-393

Hairston NG (1996) Zooplankton egg banks as biotic reservoirs in changing environments. Limnol Oceanogr 41: 1087-1092

Hansen JP, Wikström SA, Axemar H, Kautsky L (2011) Distribution differences and active habitat choices of invertebrates between macrophytes of different morphological complexity. Aquat Ecol 45:11-22

Heino J (2000) Lentic macroinvertebrate assemblage structure along gradients in spatial heterogeneity, habitat size and water chemistry. Hydrobiologia 418:229-242

Heino J, Muotka T, Paavola R (2003) Determinants of macroinvertebrate diversity in headwater streams: regional and local influences. J Anim Ecol 72:425-434

Henrikson BI (1993) Sphagnum mosses as a microhabitat for invertebrates in acidified lakes and the colour adaptation and substrate preference in Leucorrhinia dubia (Odonata, Anisoptera). Ecography 16:143-153

Kuczýnska-Kippen N (2008) Spatial distribution of zooplankton communities between the Sphagnum mat and open water in a dystrophic lake. Pol J Ecol 56:57-64
Lande R (1996) Statistics and partitioning of species diversity, and similarity among multiple communities. Oikos 76:5-13

K Ligeiro R, Melo AS, Callisto M (2010) Spatial scale and the diversity of macroinvertebrates in a Neotropical catchment. Freshw Biol 55:424-435

Lucena-Moya P, Duggan IC (2011) Macrophyte architecture affects the abundance and diversity of littoral microfauna. Aquat Ecol 45:279-287

*McAbendroth L, Ramsay PM, Foggo A, Rundle SD, Bilton DT (2005) Does macrophyte fractal complexity drive invertebrate diversity, biomass and body size distributions? Oikos 111:279-290

*Melo TX, Medeiros ES (2013) Spatial distribution of zooplankton diversity across temporary pools in a semiarid intermittent river. Int J Biodivers 2013:1-13

*Mergeay J, Declerck S, Verschuren D, Meester LD (2006) Daphnia community analysis in shallow Kenyan lakes and ponds using dormant eggs in surface sediments. Freshw Biol 51:399-411

Minshall GW (1988) Stream ecosystem theory: a global perspective. J N Am Benthol Soc 7:263-288

* Mormul RP, Thomaz SM, Takeda AM, Behrend RD (2011) Structural complexity and distance from source habitat determine invertebrate abundance and diversity. Biotropica 43:738-745

Nielsen DL, Smith FJ, Hillman TJ, Shiel RJ (2000) Impact of water regime and fish predation on zooplankton resting egg production and emergence. J Plankton Res 22: 433-446

Oksanen J, Kindt R, Legendre P, O'Hara B, Simpson GL, Solymos P, Wagner H (2009) Vegan: community ecology package. $\mathrm{R}$ package version 1.15-2, https://cran.rproject.org/web/packages/vegan/index.html

* Poff NL (1997) Landscape filters and species traits: towards mechanistic understanding and prediction in stream ecology. J N Am Benthol Soc 16:391-409

R Development Core Team (2009) R: a language and environment for statistical computing. R Foundation for Statistical Computing, Vienna

Santangelo JM (2009) Estrutura do banco de ovos de resistência em sistemas aquáticos continentais e influência da salinidade e da predação na diapausa. $\mathrm{PhD}$ dissertation, Universidade Federal do Rio de Janeiro

Silva LNM (2002) Estrutura de uma turfeira de altitude no município de São José dos Ausentes (RS-Brasil). MS dissertation, Universidade Federal do Rio Grande do Sul, Porto Alegre

SPSS (2009) PASW Statistics 18. SPSS, Chicago, IL

Stenert C, Bacca RC, Mostardeiro CC, Maltchik L (2008) Environmental predictors of macroinvertebrate communities in coastal wetlands of southern Brazil. Mar Freshw Res 59:540-548

* Stenert C, Ehlert B, Ávila AC, Sousa FDR, Esquinatti FM, Batzer DP, Maltchik L (2016) Dormant propagule banks of aquatic invertebrates in ponds invaded by exotic pine species in southern Brazil. Mar Freshw Res, doi:10.1071/ MF16067

Taniguchi H, Tokeshi M (2004) Effects of habitat complexity on benthic assemblages in a variable environment. Freshw Biol 49:1164-1178

Tarr TL, Baber MJ, Babbitt KJ (2005) Macroinvertebrate community structure across a wetland hydroperiod gradient in southern New Hampshire, USA. Wetlands Ecol Manage 13:321-334 
Thomaz SM, Cunha ERD (2010) The role of macrophytes in habitat structuring in aquatic ecosystems: methods of measurement, causes and consequences on animal assemblages' composition and biodiversity. Acta Limnol Bras 22:218-236

Thomaz SM, Dibble ED, Evangelista LR, Higuti J, Bini LM (2008) Influence of aquatic macrophyte habitat complexity on invertebrate abundance and richness in tropical lagoons. Freshw Biol 53:358-367

Veech JA, Crist TO (2007) Habitat and climate heterogeneity maintain beta-diversity of birds among landscapes within ecoregions. Glob Ecol Biogeogr 16:650-656

Editorial responsibility: Victor Benno Meyer-Rochow, Oulu, Finland
Warfe DM, Barmuta LA (2004) Habitat structural complexity mediates the foraging success of multiple predator species. Oecologia 141:171-178

Whittaker RH (1960) Vegetation of the Siskiyou mountains, Oregon and California. Ecol Monogr 30:279-338

Whittaker RH (1972) Evolution and measurement of species diversity. Taxon 21:213-251

Williams D (1998) The role of dormancy in the evolution and structure of temporary water invertebrate communities. Arch Hydrobiol 52:109-124

Williams D (2006) The biology of temporary waters. Oxford University Press, New York, NY

Submitted: July 18, 2016; Accepted: November 10, 2016

Proofs received from author(s): December 12, 2016 